\title{
Modelo climático para previsão do míldio da cebola
}

\author{
Leandro Luiz Marcuzzo ${ }^{1}$, Erlei Melo Reis ${ }^{2}$
}

${ }^{1}$ Instituto Federal Catarinense - IFC/Campus Rio do Sul, CP 441, CEP 89.163-356, Rio do Sul, SC; ${ }^{2}$ OR Sementes, CEP 99050-120, Passo Fundo, RS.. Autor para correspondência: Leandro Luiz Marcuzzo (marcuzzo@ifc-riodosul.edu.br)

Data de chegada: 15/08/2014. Aceito para publicação em: 26/08/2015.

$10.1590 / 0100-5405 / 2028$

\section{RESUMO}

Marcuzzo, L.L.; Reis, E.M. Modelo climático para previsão do míldio da cebola. Summa Phytopathologica, v.42, n.1, p.103-104, 2016.

\begin{abstract}
A partir de dados publicados na literatura, elaborou-se um modelo de previsão do míldio da cebola, causado por Peronospora destructor. O modelo desenvolvido baseia-se nas condições climáticas favoráveis para o processo infeccioso, baseado na temperatura e na duração do molhamento foliar. Obtevese a interação que representa os dois fatores sobre a probabilidade de infecção. Com auxílio da planilha eletrônica Excell, calculou-se a duração do período
\end{abstract}

de molhamento foliar para obter diferentes probabilidades de infecção do patógenos em diferentes temperaturas. Com os dados foi elaborada uma tabela que poderá ser usada na programação computacional que registra a duração do período de molhamento foliar e a temperatura média e automaticamente o valor diário de probabilidade de ocorrência de infecção. O modelo será validado em experimentos conduzidos no campo e com infecção natural, em Rio do Sul, SC.

Palavras-chave: Allium cepa, Peronospora destructor, previsão de doenças

\section{ABSTRACT}

Marcuzzo, L.L.; Reis, E.M. Climatic model to forecast onion downy mildew. Summa Phytopathologica, v.42, n.1, p.103-104, 2016.

Data available in the literature were used to develop a model to forecast onion downy mildew caused by Peronospora destructor. The developed model is based on weather conditions favorable to the infectious process, according to temperature and leaf wetness duration. The interaction that represents the two factors on the probability of infection was obtained. Using Excel sheet, leaf wetness duration was calculated to obtain different probabilities of infection by pathogens at different temperatures. These data were employed to create a table that can be used in computer programming to record leaf wetness duration and average temperature and, automatically, the daily value of probability of infection occurrence. The model will be validated in field experiments under natural infection in Rio do Sul, Santa Catarina State, Brazil.

Keywords: Allium cepa, Peronospora destructor, plant disease forecasting.

O míldio da cebola causado por Peronospora destructor (Berk.) Casp. é uma importante doença da cultura quando coincidem temperaturas amenas e condições de molhamento foliar (7).

$\mathrm{O}$ efeito do ambiente sobre o processo infeccioso de $P$. destructor têm sido relatado por Sutton \& Hildebrand (5), porém complexo de ser utilizado como um sistema de previsão computadorizado e prático ao agricultor em nível de campo. Hildebrand \& Sutton (1) avaliaram a interação de diferentes durações de molhamento foliar e temperatura sobre a infecção do míldio em folhas de cebola, porém sem o uso destes como um sistema de previsão.

O estabelecimento de uma doença depende da interação entre ambiente, patógeno e hospedeiro. Com relação ao ambiente, a temperatura e o molhamento foliar são fundamentais para o processo epidemiológico, sendo à base de um modelo climático (4). O modelo climático fundamenta-se no efeito do ambiente sobre o processo infeccioso, onde após os esporos do patógeno estarem depositado na planta o processo irreversível de infecção responde ao estímulo do ambiente como a temperatura e a presença de água livre na superfície do hospedeiro $(6,8)$. Portanto o modelo climático prevê a infecção (germinação, crescimento do tubo germinativo, penetração do hospedeiro e estabelecimento do parasitismo) e será sucedida quando o molhamento for de duração suficiente, a uma temperatura média para dar inicio a colonização do hospedeiro. Nessa interação
Zadoks \& Schein (8) denominaram de período crítico (PC). Portanto após ocorrer um PC, pode secar a superfície da folha que o patógeno dará continuidade ao seu ciclo de vida, pois já ocorreu o estabelecimento do parasitismo.

O presente trabalho teve como objetivo desenvolver um sistema de previsão para o míldio da cebola baseado no modelo climático.

Sistemas de previsão podem ser obtidos através de informações disponíveis na literatura. Nesse trabalho utilizaram-se os dados da publicação de Hildebrand \& Sutton (1), onde constam valores das interações entre seis temperaturas e seis tempos de molhamento foliar sobre a infecção de $P$. destructor para gerar a equação. Com a equação gerada e utilizando-se a planilha eletrônica Excell (Microsoft, 2007), colocando-se nas células a infecção desejada do míldio expressa como Favorabilidade de infeção (0 a 100\%) e a temperatura $\left(6\right.$ a $\left.26^{\circ} \mathrm{C}\right)$, tomou-se a duração de molhamento foliar (hm) como incógnita, calculou-se sua duração para causar probabilidades desejadas de infecção do patógeno. Os efeitos da temperatura foram calculados em intervalos de $1,0^{\circ} \mathrm{C}$ e das variações de molhamento em intervalos de 1,0 hora de duração. No presente trabalho eles foram denominados de valores diários de probabilidade de infecção (VDPI). Com esse procedimento elaborou-se uma tabela com os VDPIs para produzir as intensidade de doença de $0,1,2,3$. 
Os valores de favorabilidade de infecção em função da temperatura e da duração do molhamento foliar dos sítios de infecção em horas e a dessa interação encontra-se na Tabela 1 .

Segundo Sutton (6) cada patógeno tem uma interação entre o período de molhamento e temperatura para completar seu ciclo de infeção, os quais podem ser visualizados para a $P$. destructor na Tabela 1. O autor cita que o efeito dessas interações sobre a infecção obtidos em condições controladas pode haver alterações quando utilizadas em nível de campo. Uma das maneiras para redimir esse processo é dividir os dados de resposta infecção em diferentes valores diários de probabilidade de infecção (VDPI) (Tabela 1). Madden et al. (3) no desenvolvimento da tabela de períodos críticos com base no modelo climático de previsão atibuiram valores arbitrários para indicar a probabilidade diária de ocorrência de infecção o qual foram denominados de valores diários de severidade (VDS) (2). Com base nesse proposto elaborou-se a Tabela 1 , com os VDPIs de cada intesidade teórica de doença que variou de 0 a 3 . A intensidade 0 corresponde a ausência da sintomas; 1 varia de 1 a $24 \%$; 2 de 25 a $49 \%$ e $3=>50 \%$ de incidência da doença nas folhas da cebola.

Tabela 1. Interações entre temperaturas $\left({ }^{\circ} \mathrm{C}\right)$ e duração do molhamento foliar (h) para causar diferentes valores diários de probabilidade de infecção (VDPI) de Peronospora destructor em folhas de cebola

\begin{tabular}{lcccc}
\hline Temperatura $\left({ }^{\circ} \mathrm{C}\right)$ & \multicolumn{5}{c}{ Valores diários de probabilidade de infecção (VDPI) } \\
\cline { 2 - 5 } & 0 & 1 & 2 & 3 \\
\hline 6 & $<2$ & 3 & $>3$ & - \\
10 & $<2$ & 2 & $>2$ & - \\
14 & $<2$ & 3 & $>3$ & - \\
18 & $<2$ & 3 & 4 & $>4$ \\
22 & $<4$ & 4 & 5 & $>10$ \\
26 & $<6$ & 10 & $>10$ & - \\
\hline
\end{tabular}

VDPI, $0=$ ausência da doença; $1=1-24 \% ; 2=25-49 \% ; 3=>50 \%$ de incidência. Tabela obtida com dados de Hildebrand \& Sutton (1).
Em experimento futuros conduzidos no campo, com infecção natural do míldio, será determinado o valor numérico da soma dos Valores Diários de Probabilidade de infecção (SVDPI). O valor do SVDPI será usado como indicador do momento da primeira aplicação de fungicida na cultura da cebola objetivando o controle da doença alvo do sistema.

Baseado nisso, os modelos de previsão de doenças de plantas são representações da realidade e prevêem o início ou o desenvolvimento futuro de uma doença, alertando para o momento de controle e podem ser desenvolvidos a partir de dados presentes na literatura desde que contemplem interações entre temperatura e períodos de molhamento foliar e seu efeito na intensidade da doença.

\section{REFERÊNCIAS BIBLIOGRÁFICAS}

1. Hildebrand, P.D.; Sutton, J.C. Relationships of temperature, moisture, and inoculums density to the infection cycle of Peronospora destructor. Canadian Journal Plant Pathology, Ottawa, v.6, p.127-134, 1984.

2. Krause, R.A.; Massie, L.B. Predictive systems: modern approaches to disease control. Annual Review of Phytopathology, Palo Alto, v.13, p.31-47, 1975.

3. Madden, L.; Pennypacker, S.P.; McNab, A.A. FAST, a forescast system for Alternaria solani on tomato. Phytopathology, St. Paul, v.68, n.9, p.1354-1358, 1978.

4. Reis, E.M. Previsão de doenças de plantas. Passo Fundo:UPF, 2004. 316p.

5. Sutton, J.C. Predictive value of weather variables in the epidemiology and management of foliar disease. Fitopatologia Brasileira, Brasília, v.12, n.4, p.305-312, 1988.

6. Sutton, J.C.; Hildebrand, P.D. Environmental water in relation to Peronospora destructor related pathogens. Canadian Journal Plant Pathology, Ottawa, v.6, p.323-330, 1985.

7. Wordell Filho, J.A.; Boff, P. Doenças de origem parasitária. In: Wordell Filho, J.A.; Rowe, E.; Gonçalves, P.A.S.; Debarba, J.F.; Boff, P.; Thomazelli, L.F. Manejo fitossanitário na cultura da cebola. Florianópolis: EPAGRI, p.19-162, 2006

8. Zadoks, J.C.; Schein, R.D. Epidemiology and plant disease management. New York: Oxford University Press, 1979. 427p. 